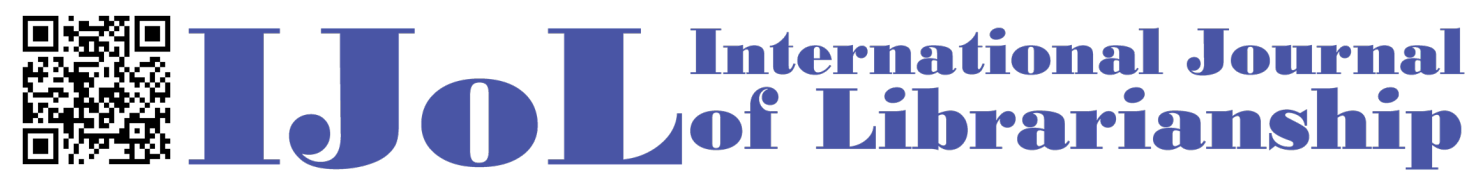

ISSN: 2474-3542 Journal homepage: https://journal.calaijol.org

\title{
FOLIO and Smart Libraries: \\ Meeting the Future Needs of Chinese Libraries
}

Wei Liu

\begin{abstract}
:
The vision and concept of FOLIO have gained the attention and expectation from libraries. It is an open and flexible service platform which provides an approach to the realization of the Smart Libraries in the future. Through summarizing the needs of Smart Libraries in China, the paper expounds the architecture and ideas of providing smart services based on FOLIO. By analyzing the problems and challenges in the implementation and localization of FOLIO in China, the author points out that the "Chinese Alliance for Library Service Platform" (also called YunHan Alliance) should play a very important role in shaping the Chinese FOLIO community. It should steward the direction of the community, cultivate an ecosystem around FOLIO, and support the new business models for the success of Chinese libraries in the future.
\end{abstract}

To cite this article:

Liu, W. (2021). FOLIO and Smart Libraries: Meeting the Future Needs of Chinese Libraries. International Journal of Librarianship, 6(2), 73-83. https://doi.org/10.23974/ijol.2021.vol6.2.213

To submit your article to this journal:

Go to https://ojs.calaijol.org/index.php/ijol/about/submissions 


\title{
FOLIO and Smart Libraries:
}

\section{Meeting the Future Needs of Chinese Libraries}

\author{
Wei Liu, Shanghai Library, Shanghai, China
}

\begin{abstract}
The vision and concept of FOLIO have gained the attention and expectation from libraries. It is an open and flexible service platform which provides an approach to the realization of the Smart Libraries in the future. Through summarizing the needs of Smart Libraries in China, the paper expounds the architecture and ideas of providing smart services based on FOLIO. By analyzing the problems and challenges in the implementation and localization of FOLIO in China, the author points out that the "Chinese Alliance for Library Service Platform" (also called YunHan Alliance) should play a very important role in shaping the Chinese FOLIO community. It should steward the direction of the community, cultivate an ecosystem around FOLIO, and support the new business models for the success of Chinese libraries in the future.
\end{abstract}

Keywords: FOLIO, Next Generation Library Services Platform, Smart Libraries, Open Source Software

\section{INTRODUCTION}

In 2010s, as the results of a natural development of digital libraries, smart libraries quickly emerged in China. In response to the concept of "smart" and the needs of libraries, vendors have developed new library applications, such as statistical analysis, resource recommendations, etc., that makes the public gradually take the smart library as a form of future libraries. However, the so-called "the next generation of library service platforms" was soon commercially available, it has not been universally recognized because the industry has not agreed on new modules other than traditional services and it lacked basic standards. Until recently, a more advanced technology architecture, namely, the cloud-native architecture, was introduced to accommodate business expansion and flexible changes, supporting ever-improving gradients to iterate application upgrades, and maximizing investment benefits in a resource reuse manner. This is the FOLIO platform.

Since 2016, the research and development of FOLIO has been bearing the weight of compatibility with "legacy". Though being the latest platform designed from the ground up, with the powerful cloud-native technology, hoping to change libraries, it can't move forward easily. Libraries need to take the advantage of FOLIO to bring the cultural accumulation of the print age into the digital age. Without a thorough understanding of the library catalogs, processing workflow, 
Liu / International Journal of Librarianship 6(2)

vocabulary, knowledge descriptions and organizations accumulated over the centuries, and even the ideas and perspectives of the world, it is impossible to build an excellent platform and be recognized by the whole industry. FOLIO is ultimately going to be a platform for libraries, not just an application of the latest IT technology, and thus it has to be rooted in the community, relying on library experts to take the direction. At present, the backbone of FOLIO is a group of senior library professional idealists who have been adhering to the principle of openness and democracy and have been practicing the professional creed of equality and inclusion when promoting the development of FOLIO and community building, but it also contains the perfectionism and intransigence, which may put FOLIO in the quagmire. Of course, the biggest challenge for an open source platform is not whether it is perfect, but how to survive and grow. In the fierce competitions, FOLIO needs to unite as many like-minded partners as possible to find an appropriate business model, otherwise it can only become a utopia in a lofty cause.

\section{VISION, OBJECTIVES, AND INITIATIVES}

FOLIO's vision is included in its full name, that is, "the future of libraries is open". It means that FOLIO hopes to support the evolving needs of global libraries with a platform that serves us now and into the future by building an open community.

FOLIO generally refers to three things: first, a platform system that meets the basic requirements of the "next generation of library service platform"; second, a group of Apps that can meet the functional requirements for the current operation and future development of libraries; third, a well-functioning and healthily developing community. Only by building a good community can we build a sustainable industrial ecology, and can we guarantee the realization and sustainable development of the above-mentioned vision and goals.

It's not easy to accomplish any one of the three goals, especially for an open community. It might be relatively easy to develop a new generation of technology-leading "platform plus applications" solutions. Compared with private companies, FOLIO faces enormous challenges due to higher requirements in terms of openness, flexibility, scalability, as well as efficiency issues in the investment and management of development resources. This has been noticeable from the development process of the FOLIO community since 2016. So far, it has been plagued by the shortage of resources and manpower, with the direct result that the development progress is behind schedule.

Building librarians' own communities is the most unique, yet most difficult part of FOLIO. Can commercial companies build communities? Possibly. For the sake of interest, however, the community built by a commercial company is just its own community. The strongest ability of companies such as Apple and Amazon is to build an industrial ecosystem, which will always be private, no matter how open it is, and users will never be the masters of the community. In contrast, the FOLIO platform is completely open in theory and belongs to the community. Of course, how to reflect this at the operational level requires specific system design. In this respect, the improvement of the FOLIO community is still in progress.

Generally speaking, FOLIO has achieved robust development so far with gratifying results. Since the release of the first landmark named version of Aster in January 2019, FOLIO has entered the fast lane of productization. With three releases per year presently, it has been iterated to the 10 th version - the Juniper release, each adding hundreds of new features and fixing found errors 
that keep the code highly available at all times. Its implementation status is also encouraging with 30 libraries fully or partially online in less than two years since it was first available at Chalmers University in Sweden in December 2019. What's more, there are more than 2,400 people active on Slack year-round, more than 15 development teams stably kept, and over 200 people contributed to the FOLIO project.

\begin{tabular}{|c|c|c|}
\hline Live today & In Implementation & \\
\hline $\begin{array}{l}\text { - Chalmers University of } \\
\text { Technology, Sweden } \\
\text { - Missouri State } \\
\text { University* } \\
\text { - National Library of } \\
\text { Florence, Italy } \\
\text { - St. Thomas Univ., FL } \\
\text { - Warner Univ. } \\
\text { - Washington and } \\
\text { Jefferson College } \\
\text { - Cornell Univ (ERM) } \\
\text { - Five College } \\
\text { Consortium (ERM) }\end{array}$ & $\begin{array}{l}\text { - } \quad \text { Five College Consortium (full FOLIO) } \\
-\quad \text { Amherst College } \\
- \text { Hampshire College } \\
- \text { Mount Holyoke College } \\
-\quad \text { Smith College } \\
-\quad \text { UMass Amherst } \\
\text { - } \quad \text { University of Alabama } \\
\text { - } \quad \text { Cornell University (full FOLIO) } \\
\text { - } \quad \text { Michigan State University } \\
\text { - } \quad \text { California Institute of Technology } \\
\text { - } \quad \text { Trinity College, Cambridge, UK } \\
\text { - } \quad \text { Grand Valley State University } \\
\text { - } \quad \text { Middle Tennessee State University } \\
\text { - } \quad \text { Lafayette College } \\
\text { - } \quad \text { Flagler College } \\
\text { - } \quad \text { St. Michael's College }\end{array}$ & $\begin{array}{ll}\text { - } & \text { Skidmore College } \\
\text { - } & \text { U of Tennessee-Martin } \\
\text { - } & \text { U de Concepcion, Chile } \\
\text { - } & \text { U de Zaragoza, Spain } \\
\text { - } & \text { U of Liverpool (ERM) } \\
\text { - } & \text { U of Modena and } \\
& \text { Reggio Emilia, Italy } \\
& \text { (ERM) } \\
\text { - } & \text { Villanova University } \\
\text { - } & \text { Widener University } \\
& \text { (ERM) } \\
\text { - Chapman University } \\
\text { (ERM) } \\
\text { - MacEwan University } \\
\text { (ERM) } \\
\text { - Truman State University } \\
\text { (ERM) ...\& others... }\end{array}$ \\
\hline
\end{tabular}

FOLIO - an active, mature software project

The Numbers

- 268 Repositories

- 208 contributors

- 3 Releases per year

. 17 teams

- 15 Product Owners

- 7 Scrum Masters

(We are primarily Scrum)
Key Quality metrics tracked:

- Unit test code coverage $(80 \%+)$

- Automated test coverage $(80 \%+)$

- Performance targets

- Regression rate

- Escaped defects

There are some unique advantages of the FOLIO open-source community that are generally expected for: first, the implementation is designed for novice and is easy to get started with, and the software meets the application needs of most small- and medium-sized libraries; second, FOLIO offers a wide range of choices of applications, which are not limited to commercial products; third, FOLIO is designed to be easily integrated, facilitating interconnection and business innovation; fourth, FOLIO faces the future by adapting to changes, such as the massive needs of smart libraries. It's almost impossible for commercial platforms to have these advantages. That's why the industry is optimistic about FOLIO.

The FOLIO community knows very well that its claimed advantages will ultimately be achieved through the platform developed and its subsequent support services to truly gain a foothold. The main tasks proposed by the FOLIO community in recent years have reflected its awareness of the severe issues in the library industry today: 
Liu / International Journal of Librarianship 6(2)

FOLIO provides above-average solutions in terms of functionality, quality, performance, stability, user experience, and implementation methods, and addresses the current general dissatisfaction of libraries with platform and system software.

FOLIO provides a cost-effective and highly competitive solution, allowing more libraries to use the most advanced platform.

FOLIO builds a community ecology, allowing the "platform plus applications" model to land in the library industry and enabling the platform to truly serve the business and to iteratively evolve.

If the FOLIO community follows the current goals and guidelines, its future is promising.

\section{NEEDS FOR SMART LIBRARIES}

\section{The Proposal of Smart Libraries}

Since the 21st century, the uncertainty of the entire world has increased significantly. Some scholars believe that we are ushering into the VUCA era (VUCA refers to Volatility, Uncertainty, Complexity, and Ambiguity). The COVID-19 pandemic has had a huge impact on human life. We need to pay more attention to changes in the environment, while maintaining our original intentions, adjusting our adaptability, researching problems, making multiple plans, responding swiftly, and managing changes as the new normal. The key to making it happen is to strengthen the ability to control technology, which is also our weapon to deal with VUCA. In the past two years, we have seen the strong interests of capital investment in mixed reality, virtual communication, contactless services, social network tracking, privacy protection, digital twins, metaverse, etc. Many companies have invested heavily in the research and development of these products, which has begun to affect people's daily life and work: home office has become the norm and is getting increasingly efficient; cultural education and entertainment industries are accelerating virtualization; and libraries are also under the pressure of accelerating its transformation.

Due to the network intelligence of e-commerce and government services in recent years, library users in China have put forward high demands on library services, hoping that new technologies can make libraries smarter. This has brought two obvious trends to the library industry:

first, it is hoped to provide more automated and unmanned services in the library space, such as self-return and checkout, online borrowing and lending services, navigation, reference services, information publishing and more. Some of these services are delivered by robots. In addition, lighting, air conditioning, elevator, curtains and some other equipment can be automatically adjusted according to environmental changes. Second, it is also hoped to provide more personalized services based on big data analytics, such as personalization of search interface and result sorting, automatic recommendation, notification, etc. This is the basic demand of the Chinese library community for "smart libraries".

It is difficult for the existing library IT architecture to be flexibly expanded. The original application is a stovepipe system with independent functions that doesn't support data sharing or module reuse. Any changes or new requirements of the libraries can't be fulfilled at a reasonable cost and always need new solutions. If there is no mature software on the market, customized development is required which often brings a lot of problems in operation and maintenance. As a 
Liu / International Journal of Librarianship 6(2)

result, it is impossible to stack up features in this technical environment. Even some leading libraries in the industry are not well placed to meet the needs, though they have already adopted cloud services. The emergence of FOLIO has given many libraries a glimpse into the direction of overhauling their IT infrastructure.

\section{Functional Requirements of Smart Libraries}

The demand for system platforms in European and American libraries seems to pay more attentions to the replacement of the current system compared with Chinese libraries, usually because the current system can no longer meet the needs and must be functionally beyond the current system, for example, whether it is able to be integrated in a better way, whether it has greater flexibility, more openness, support for community interaction, and whether it has the ability to solve problems in digital resource management and services, and so on. In contrast, libraries in China seem to care more about the extension of functions. Without new functions, they usually lack the motivation to replace the old system unless it is completely out of use. However, if the old system is not "compatible" with new functions in some way, libraries might abandon the old system because of the desire for "innovation", even though the new platform may simply be "compatible" with thirdparty systems rather than directly providing new features. This is why the current concept of "smart libraries" has received great attention in China. People's expectation for FOLIO is to bring library services to a new level, where the ability to fully support "smart services" is a big factor.

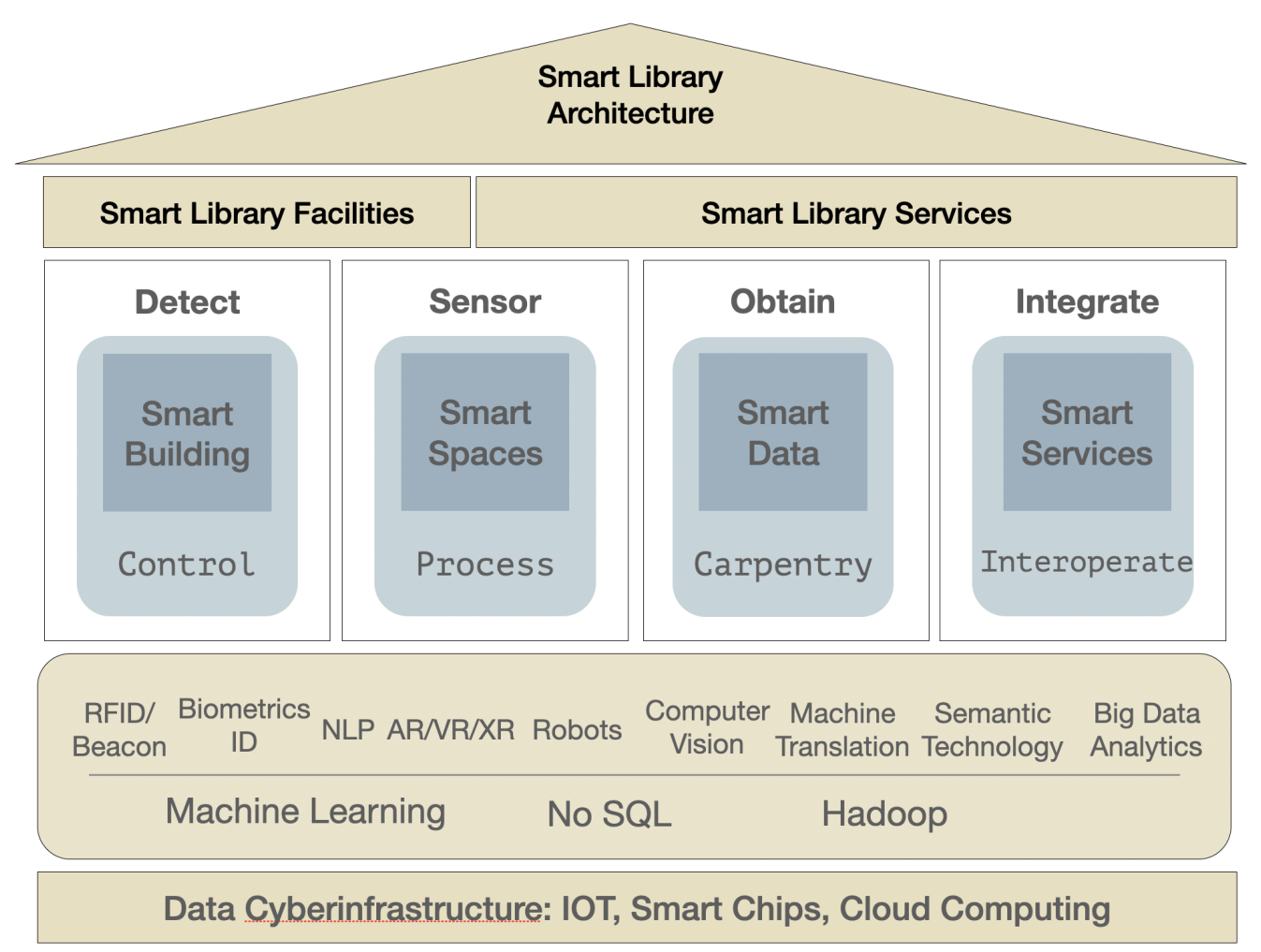

Figure 1. Structure of Smart Library Systems 
The above image is a structure of the Smart Library System that can be used to explain the popular concept of "smart library" in China. The bottom layer is the infrastructure of the smart city. The technical layer above contains various related technologies, among which "machine learning" is placed in a relatively important position as it is a key technology in all smart systems today. Further up are the four types of technical systems of smart libraries (as detailed below), which together constitute the products and services of smart libraries.

1) Intelligent buildings will become a must-have to libraries in the future. At present, the construction of public buildings in China has mandatory requirements to implement intelligent building standards. Even the old library buildings can be upgraded to intelligent ones with selfsensing systems. Therefore, many libraries have started to use BIM technologies to explore the intelligent management of library facilities during the renovation of old buildings and the construction of new ones, applying them to firefighting, security, monitoring, operation, early warning, energy saving and other aspects. They can also be combined with library space management, and even connect with business systems to automatically control daylighting, elevators, air conditioning, parking, access control, people flow, logistics, equipment and facilities.

2) Smart space mainly refers to the space-related services provided to users. The basic capabilities are built on the BIM system, which needs to open its API and even control interfaces. Related functions mainly include reservations (seats, venues, events, books, etc.), navigation, information release, recommendations, reminders, and more.

3) Smart data is the basis for libraries to provide smart services and also the main purpose of smart business. Smart data refers to data that has a semantic description, can be explained in the system environment, or can be "actionable". The libraries' work related to smart data includes the smartization of resource data (through processing and organization) and the analysis and mining of transaction data.

4) Smart services, usually classified according to the type of resources and workflow, refers to work items set up by libraries to achieve their institutional goals. People treat libraries as a place to "borrow and return" because of their traditional services. Strictly speaking, "borrow and return" is a library service; while "acquisition", "cataloging", "inventory" and other work behind the scene are also the works to support library services. Since the 1980s, library services have gone beyond borrowing and returning by adding "reference consultation", "conferences and exhibitions", "workshops" and other services. In the 21 st century, new service methods, such as shared space, maker space, reading promotion, digital reading, are further developed. In order to manage these services, the back-end workflow and software systems have been greatly expanded, which requires a powerful "next generation of library service platform" with data and AI middle platforms to analyze data and to empower library services to have smart ability.

\section{How Does FOLIO Provide Smart Services}

The "platform plus applications" model of FOLIO provides sufficient flexibility and scalability to enable the functions of smart libraries to be embedded and thrive. Based on the FOLIO architecture as a blueprint, a cloud-native microservice architecture with Chinese features is introduced. The reason that we call it "with Chinese features" lies in the introduction of the concept of middle platforms, i.e., middle-ends residing between the front-end and the back-end, including business middle, technology middle, data middle and AI middle. 
Liu / International Journal of Librarianship 6(2)

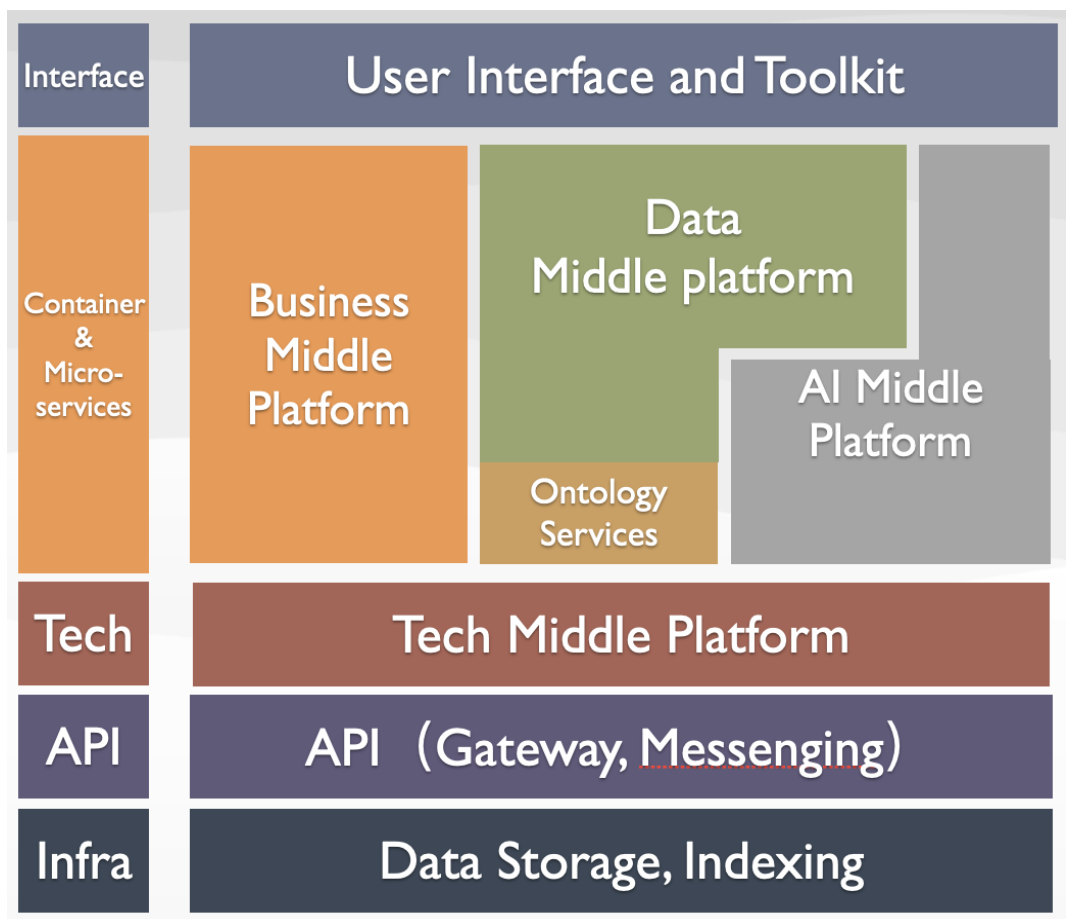

Figure 2. Middle Platforms of the Smart Library Architecture

The "middle platform" means taking out the reusable parts of the cloud platform applications and combining them into more efficient and targeted services so that the entire system can meet the front-end needs of flexibility, scalability and responsiveness to changes and can also provide comparative stability to data storage and business logic at the bottom. This is equivalent to providing a set of gearboxes between the front-end and the back-end.

The concept of "middle platform" was developed by Jack Ma (Chinese name Ma Yun), the co-founder and former executive chairman of Alibaba Group, when he visited the Finnish game company Supercell in 2015. At that time, the organizational structure of the game company addressed a management bottleneck for the rising Chinese Internet company, that is, the complexity of management had increased exponentially and almost reached an uncontrollable state with the rapid expansion of the company's scale and the rapid growth of its business. After Jack returned to China, he put forward the concept of "big middle-end and small front-end", which enabled front-end services to be lightly packed, while allowing the supporting team to focus on the reuse of capabilities as well as the integration and empowerment of resources. The "middle platform" methodology has become a conceptual framework for architectural design for China's cloud service companies.

This concept can also be incorporated in the design of the FOLIO platform with smart services to provide libraries with a full range of technical support for their management, business, services and so on. As its technical architecture supports flexible scalability, it is no longer limited to the few basic modules of the integrated management system such as acquisition, cataloging and circulation. Instead, it can be extended as wished to accommodate the service needs of smart libraries. Its middle platform design is able to reuse the basic functions and data such as that of the reader management and resources management, without designing new modules. 
Liu / International Journal of Librarianship 6(2)

However, the construction of smart libraries is a long and arduous process with much work in platform development, especially the standardization work. The traditional ILS has achieved great success and has been popular for decades, with a set of systems being used throughout the industry, mainly thanks to the standardization of data formats and business processes. In comparison, smart libraries still have a long way to go. It is necessary to conduct in-depth research and discussions on a large number of smart services (including smart space services), establish basic requirements and procedures, develop corresponding specifications, standardize them as soon as possible and obtain recognition from the industry.

\section{FOLIO AND THE FUTURE OF CHINESE LIBRARIES}

The current development model of FOLIO cannot fully take into account the needs of China and some other regions and areas. There are many differences among China and Western countries in terms of product naming, functional modules, platform operations, and business models. In addition to technical factors, FOLIO also needs to consider society, culture, industrial ecology, institutional factors and related markets in order to succeed in the Chinese library community. This is mainly manifested in the following aspects:

First, Chinese users attach great importance to the localization of software. They are very concerned about whether local cultural habits can be respected by others, the most important of which is the localization of language and experience, such as Chinese name, address, date and time format, currency, punctuation, cultural meaning of colors, typesetting, sorting method, and more. There are different conventions and it is very awkward if the proper ones are not well followed. A foreign product with a local Chinese name is often more welcomed, with less friction in its dissemination and acceptance. Nevertheless, localization needs can be of the minority in the international community and is difficult to be incorporated in the "standardized products" of the entire community, which leads to the differences of products maintained by the local community and the international community. Principles, guidelines and best practices are needed to define to what extent they can be different. However, none of this is currently on the agenda.

Second, open source software has not been well accepted yet in China. Many open source communities have just become active in recent years and have started to have a group of young fans who basically come from the IT and AI related fields. Most of the IT software and services in China are provided by commercial companies. Chinese users are not adapted to the open source model yet, especially are not good at operating "communities" and there exists some issues with the activity level and healthy interactions in many communities, that is, the community is often promoted by a small number of very passionate and dedicated people, which is very risky and has resulted in the very short life cycle of many good applications.

Third, the market for open source applications has not yet been established. Libraries are accustomed to purchasing software products instead of purchasing hosting, deployment, support, operation and maintenance services, and often do not have a budget in this aspect. In addition, open source software, especially the SaaS cloud service, involves complex product integration, operation monitoring and version management, and has not developed a mature business model yet. This will affect the quality of services that libraries provide to readers.

Fourth, the "platform plus applications" model of FOLIO ultimately needs to maintain an open application ecosystem, which requires robust platform management and core apps that rely on 
different combinations to achieve the most basic business management requirements of most libraries. This ecosystem also needs a large number of third parties to provide apps that meet all kinds of needs. These apps are basically paid apps or have their own business models, which need to be regulated. There need to be simple and clear procedures and efficient and automatic processes especially in terms of application compliance and compatibility evaluation, as well as the management of application stores. These will all bring a certain cost to the open source community.

In response to the above-mentioned problems, the Chinese community has started to make plans and is trying to carry them out in the community, which include:

First, drive development by implementation, work on product planning and localization during the development, and start building a local community.

As the first implementer in China, Shanghai Library has been fully aware of the huge differences between the open source model and traditional applications since its decision in 2018 to partner with CALIS to adopt FOLIO. Working with Shanghai Jiaotong University Library and Jiangsu Jiatu Network Technology Co., Ltd., Shanghai Library has made great efforts to unite Chinese libraries and vendors to build and support the local community.

By 2020, it has been decided that "Yunhan" (in Chinese "云瀚") will be used as the localized name for FOLIO in China. The Chinese community was initially established and is working on a roadmap and a series of product plans. Through the establishment of expert committees and alliance of member institutions, and by referring to the operation management model of international communities, mechanisms for product planning, technical decision-making, development coordination, compatibility evaluation and certification, and formulation and release of standards and specifications are being established.

Second, recruit teams to work on product planning, research and development; participate in the development work of the international community; and improve the localized product suite.

FOLIO, as a unified platform architecture, is expected to lead the IT applications of most libraries and similar institutions. The Chinese community has been actively involved in the international community, recruiting teams to participate in its research and development work, encouraging more institutions to become its members, and providing financial support for the maturity and success of FOLIO.

The Chinese community has identified two types of product users: public and academic libraries, and has vigorously developed and promoted corresponding basic suites for each type. The community has also actively recruited users and has continuously iterated products in practice. Simultaneously, it has formulated different levels of application compatibility standards and has encouraged compatibility transformation for all types of applications.

Third, with the regional user alliances in China as the main body of the community, improve the operation of the community and enhance its cohesion.

In addition to the three founding members who serve as stakeholders to provide back-end support, the current "Chinese Alliance for Library Service Platform" (Yunhan Alliance or Yunmeng) has the following general structure:

1) The Yunhan community is divided into the application community and the technical community, which are composed of libraries and companies respectively. Each institution has its 
Liu / International Journal of Librarianship 6(2)

designated representative in the community. In order to encourage more libraries and companies to join, no membership fee is considered at the current stage. The necessary cost for community operation shall be covered by donations, service income, and self-raised funds by its member institutions.

2) Improve the expert committee. The experts are individual members of the community, but not necessarily affiliated to any member institutions. Furthermore, the experts are categorized into technical, product and consulting groups, which create plans, take tasks assigned by the alliance, conduct related discussions, and compile documents.

3) The secretariat is responsible for daily affairs, including assisting the expert committee in the work, preparing community meetings, maintaining the website, operating new media and newsletters, and holding monthly workshops, etc.

4) Compile a series of community documents to standardize product operations and promote community development. The documents include:

- Yunhan Product Map

- Yunhan Product Roadmap

- Yunhan Smart Service Level \& Product Planning

- Yunhan Product Development Specifications

- Yunhan Cloud Service SLA

- Yunhan Platform Technical Specifications White Paper

- Statistics Specifications for Yunhan Data Platform

- Yunhan Platform Deployment \& Configuration White Paper

- Yunhan API Interface Specification

- Evaluation Criteria for Yunhan Product Compatibility \& Release Specifications

- App Store Management \& Operation Guide for Yunhan Community

Fourth, promote the idea of paid services to users. Work on the standardization and quality control of products and services and enrich the product formats at the same time. Develop different product suites for diverse user groups and provide implementation, deployment, hosting, support (consulting) and other standardized services. Actively reach out to potential members and provide training to help more libraries and companies join the application ecosystem.

Admittedly, the FOLIO community is still plagued by many difficulties, including insufficient resources, difficulty in ensuring the development progress, problems with decision-making and efficiency issues in terms of needs and community management. The establishment of the local community is with the aim to alleviate this issue. The local alliance should devote itself to meeting the local needs. What's more, the local community needs to learn from the international community and to keep close communication with it in order to maintain a certain degree of consistency in forking, product compatibility, business models, and ecological construction. 
Liu / International Journal of Librarianship 6(2)

\section{CONCLUSION: LET THE FUTURE OF THE LIBRARY ACHIEVE SUSTAINABLE DEVELOPMENT}

Ken Chad, an independent consultant for British libraries, made a classic judgment on the library cloud computing platform in 2016: only the platform-based ecosystem model shall be counted as the true "next generation" in library automation. The new open source solution is about the business model innovation rather than functional advances. A more open library technology ecosystem would eliminate the restrictions of a closed and monolithic suite of services from a single vendor. Cloud computing presents new opportunities to grow partnerships more easily and offers Independent Software Vendors (ISVs) tools, training and support to develop their applications. (Chad, 2016)

There are more than 3,000 province-level, city-level and county-level public libraries in China. More than 3,300 cultural centers are equipped with libraries, which serve as branches of the county libraries. Additionally, there are more than 1,000 university libraries, hundreds and thousands of primary and secondary school libraries and labor union libraries. These libraries lack professional librarians and sustainable funding. They work in silos and are not connected with each other. Therefore, it is difficult to achieve integrated management and services. Each individual library can only play a very limited role. However, if big libraries can support small ones through cloudbased platforms, the library system software will become a united platform shared by all types of libraries in the Internet Age rather than a tool owned by a single library, as it was in the past. Through the shared platform, every library can provide diverse knowledge services to its readers with the resources shared by the entire industry. If so, the revival of the library industry in the digital age will not be far away.

\section{References}

Chad, K. (2016, January). Rethinking the Library Services Platform: Briefing paper. HELibTech. http:/www.kenchadconsulting.com/wpcontent/uploads/2018/09/Rethinking_the_LSP_Jan2016a.pdf. DOI: 10.13140/RG.2.1.4989.4481

\footnotetext{
About the author

Keven Liu is the Deputy Director of Shanghai Library. He took part in many major Digital Library projects in China since 1995. He is also the Vice Chairman of Shanghai Library Society, member of the Governing Board of Dublin Core Metadata Initiative (DCMI) and the Board of Open Library Foundation.
} 